\title{
Heart toxicity from breast cancer radiotherapy
}

\section{Current findings, assessment, and prevention}

\author{
Marc D. Piroth ${ }^{1} \cdot$ René Baumann ${ }^{2,4}$ - Wilfried Budach ${ }^{3}$ - Jürgen Dunst ${ }^{4}$ Petra Feyer Rainer Fietkau $^{6}$. \\ Wulf Haase ${ }^{7}$. Wolfgang Harms ${ }^{8}$. Thomas Hehr ${ }^{9}$. David Krug ${ }^{10,14}$ • Arnd Röser ${ }^{1}$. Felix Sedlmayer ${ }^{11}$. \\ Rainer Souchon ${ }^{12} \cdot$ Frederik Wenz $^{13} \cdot$ Rolf Sauer $^{6}$
}

Received: 12 July 2018 / Accepted: 20 September 2018 / Published online: 11 October 2018

(c) The Author(s) 2018

\begin{abstract}
Background Late cardiac toxicities caused by (particularly left-sided) breast radiotherapy (RT) are now recognized as rare but relevant sequelae, which has prompted research on risk structure identification and definition of threshold doses to heart subvolumes. The aim of the present review was to critically discuss the clinical evidence on late cardiac reactions based on dose-dependent outcome reports for mean heart doses as well as doses to cardiac substructures.

Methods A literature review was performed to examine clinical evidence on radiation-induced heart toxicities. Mean heart doses and doses to cardiac substructures were focused upon based on dose-dependent outcome reports. Furthermore, an overview of radiation techniques for heart protection is given and non-radiotherapeutic aspects of cardiotoxicity in the multimodal setting of breast cancer treatment are discussed.

Results Based on available findings, the DEGRO breast cancer expert panel recommends the following constraints: mean heart dose $<2.5 \mathrm{~Gy} ; \mathrm{D}_{\text {mean }} \mathrm{LV}$ (mean dose left ventricle) $<3 \mathrm{~Gy}$; V5 $\mathrm{LV}_{\mathrm{LV}}$ (volume of $\mathrm{LV}$ receiving $\left.\geq 5 \mathrm{~Gy}\right)<17 \%$; V23 $\mathrm{LV}$ (volume of $\mathrm{LV}$ receiving $\geq 23 \mathrm{~Gy}$ ) $<5 \%$; $\mathrm{D}_{\text {mean }} \mathrm{LAD}$ (mean dose left descending artery) $<10 \mathrm{~Gy}$; V30 $\mathrm{LAD}$ (volume of LAD receiving $\geq 30 \mathrm{~Gy})<2 \%$; V40 $\mathrm{LAD}$ (volume of LAD receiving $\geq 40 \mathrm{~Gy})<1 \%$.

Conclusion In addition to mean heart dose, breast cancer RT treatment planning should also include constraints for cardiac subvolumes such as LV and LAD. The given constraints serve as a clinicians' aid for ensuring adequate heart protection. The individual decision between sufficient protection of cardiac structures versus optimal target volume coverage remains in the physician's hand. The risk of breast cancer-specific mortality and a patient's cardiac risk factors must be individually weighed up against the risk of radiation-induced cardiotoxicity.
\end{abstract}

Keywords Heart toxicity $\cdot$ Breast cancer radiotherapy $\cdot$ Breast cancer $\cdot$ Mean heart dose $\cdot$ LAD

\section{Kardiale Toxizität durch Strahlentherapie bei Brustkrebs}

Aktuelle Ergebnisse, Bewertung und Prävention

\section{Zusammenfassung}

Hintergrund Kardiale Spättoxizitäten aufgrund einer Bestrahlung der Brust (insbesondere linksseitig) sind als seltene aber relevante Folgeerscheinungen darstellbar, was weitere Untersuchungen mit Identifikation aussagekräftiger Risikostrukturen sowie folgend die Definition von Grenzdosen kardialer Subvolumina sinnvoll erscheinen lässt.

Prof. Dr. Marc D. Piroth

marc.piroth@helios-gesundheit.de

Extended author information available on the last page of the article 
Methoden Ein Literaturreview wurde durchgeführt, um die klinische Evidenz der strahlentherapieinduzierten Herztoxizität zu beleuchten. Die mittlere Herzdosis sowie auch kardiale Substrukturen wurden fokussiert, basierend auf Berichten mit Dosis-Wirkungs-Abhängigkeiten. Des Weiteren wird ein Überblick der technischen Möglichkeiten der Herzschonung gegeben und nichtradiotherapeutische Aspekte der Kardiotoxizität in der multimodalen Behandlung des Mammakarzinoms werden kommentiert.

Ergebnisse Basierend auf den verfügbaren Daten empfiehlt das Expertenpanel Mamma der DEGRO folgende Grenzwerte, um das Herz so effektiv wie möglich zu schützen: mittlere Herzdosis $<2,5 \mathrm{~Gy}$; $\mathrm{D}_{\text {mean }}$ LV (mittlere Dosis linksventrikulär) $<3 \mathrm{~Gy}$; V5 $5_{\mathrm{LV}}$ (Volumen des linken Ventrikels, das $\geq 5 \mathrm{~Gy}$ erhält) $<17 \%$; V23 $3_{\mathrm{LV}}$ (Volumen des linken Ventrikels, das $\geq 23$ Gy erhält) $<5 \%$; $\mathrm{D}_{\text {mean }} \mathrm{LAD}$ (mittlere Dosis der linken anterioren absteigenden Koronararterie) $<10 \mathrm{~Gy}$; V30 LAD (Volumen der LAD, das $\geq 30$ Gy erhält) $<2 \%$; V40 LAD (Volumen der LAD, das $\geq 40$ Gy erhält) $<1 \%$.

Schlussfolgerung Zusätzlich zur mittleren Herzdosis sollten kardiale Subvolumina, wie linker Ventrikel und LAD, mit entsprechenden Grenzwerten in die Bestrahlungsplanung des Mammakarzinoms einbezogen werden. Die Dosisgrenzwerte sollen dem Kliniker helfen, das Herz bei der Bestrahlungsplanung der Brust adäquat zu schützen. Die individuelle Entscheidung zwischen einer suffizienten Schonung kardialer Strukturen einerseits und der optimalen Zielvolumenabdeckung andererseits bleibt in der Hand des Arztes. Das Risiko der brustkrebsspezifischen Mortalität und die sonstigen kardialen Risikofaktoren des Patienten müssen individuell gegenüber möglichen strahleninduzierten Herztoxizitäten abgewogen werden.

Schlüsselwörter Herztoxizität $\cdot$ Bestrahlung bei Brustkrebs $\cdot$ Brustkrebs $\cdot$ Mittlere Herzdosis $\cdot$ LAD

\section{Background}

After breast-conserving surgery (BCS), whole-breast irradiation (WBI) with a total dose of 50 Gy reduces the local recurrence rate by $70-88 \%[1,2]$. Moreover, a $5.3 \%$ reduction in overall mortality after 15 years could be shown in favor of adjuvant radiotherapy (RT) [3].

However, it is suspected that RT of left-sided breast cancer might lead to relevant cardiac toxicities [3-5]. In early trials including breast RT, an increase in the number of cardiac deaths was observed [4] and cardiac mortality was higher in left-sided breast cancer patients than in right-sided disease [5-7]. These trials predominantly used older RT techniques, resulting in considerable doses to heart subvolumes [6-9].

Major advances in RT techniques throughout the past decades, such as three-dimensional (3D) treatment planning, have led to a continuous reduction in radiation dose to the heart. Taylor et al. comparatively analyzed mean heart doses from left tangential RT to cardiac structures over several decades, and described reductions in mean heart dose from $13.3 \mathrm{~Gy}$ in the $1970 \mathrm{~s}$, to $4.7 \mathrm{~Gy}$ in the $1990 \mathrm{~s}$, and $2.3 \mathrm{~Gy}$ in 2006 [10-12]. This decrease seems to have resulted in a very low risk of death caused by radiation-induced heart disease (RIHD), at least for women without cardiac risk factors [13].

However, it remains to be considered that despite low mean heart doses, relevant areas of the heart can be exposed to doses between 40 and 50 Gy [14], as shown exemplarily in Figs. 1 and 2. Mean heart dose-the only parameter reported in earlier studies - does not seem to reliably reflect the cardiac risk in many cases [15]. Nevertheless, the results of a recently performed practice pattern survey showed that most of the participating radiotherapists consider the mean heart dose to be the most important dose parameter related to heart sparing in breast cancer RT [16].

The dose values from the treatment planning shown in Fig. 1 and 2 ist showed in detail in Table 1. The aim of the present paper is to critically discuss whether mean heart dose should continue to be regarded as the most relevant parameter for prediction of cardiac toxicities or if dose constraints for substructures of the heart are more relevant. Furthermore, we want to give an overview of techniques to protect the heart and comment on non-radiotherapeutic aspects of cardiotoxicity in the multimodal setting of breast cancer treatment.

\section{Methods}

\section{Assessment of cardiac toxicities}

A literature review was performed to examine the published clinical evidence on radiation-induced heart toxicities (summarized in Table 2).

\section{Results}

\section{Pathophysiological findings}

Even though the pathophysiological mechanisms of radiation-induced heart damage are incompletely understood, it is known that multiple effects contribute to heart toxi- 
Fig. 1 Three-dimensional (3D) treatment plans with and without gating (transverse slides, dose-wash). Left side: 3D treatment planning without deep-inspiration breathold (DIBH) with normal breathing; right side: the same patient planned using gated breathing with DIBH. Planning target volume $(P T V)$ contoured in red, heart contoured in purple, left ventricle contoured in green, left anterior descending artery $(L A D)$ contoured in yellow

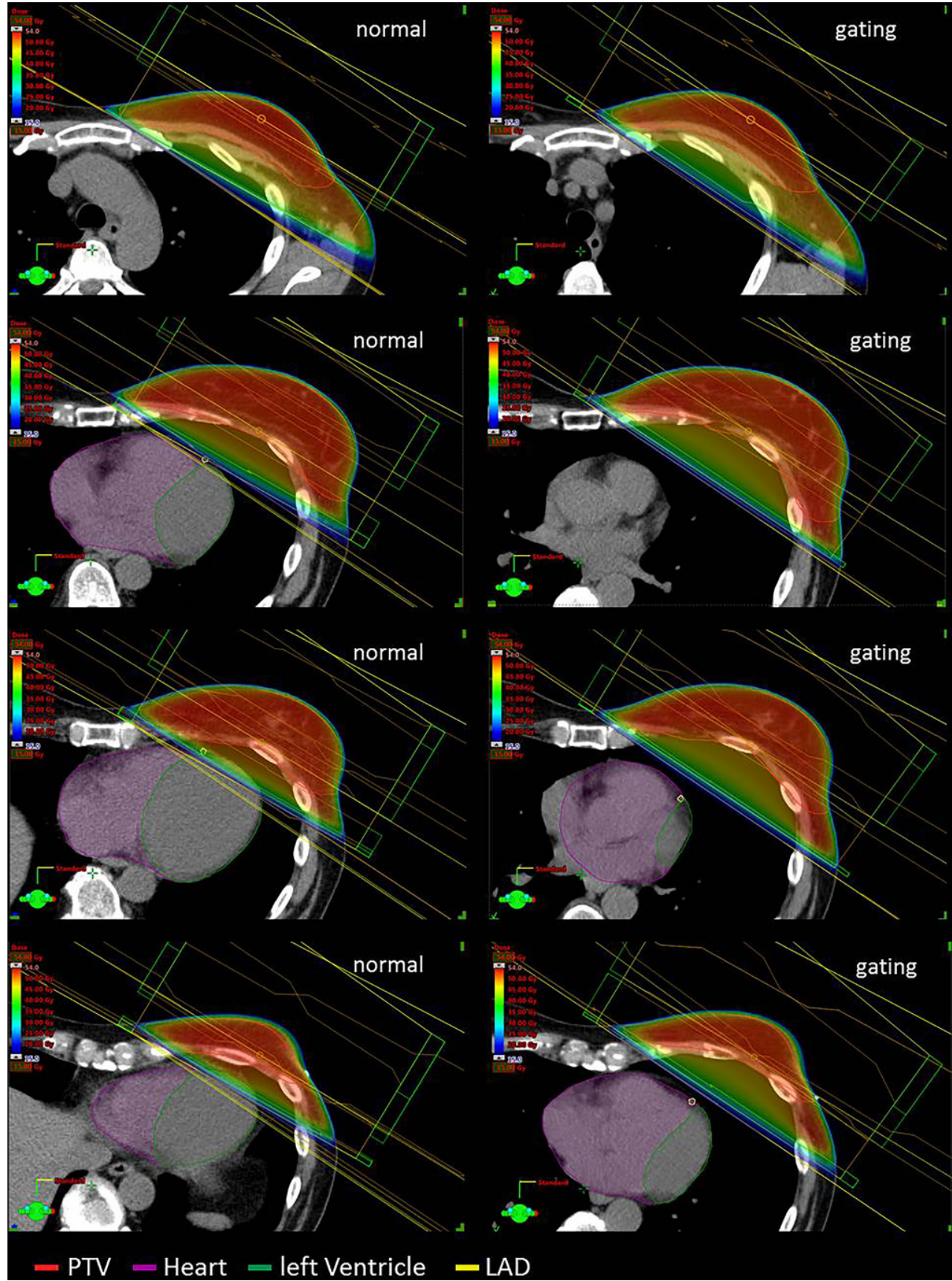

city. In vitro and in vivo studies show radiogenic effects on the micro- and macrovascular systems. These effects include inflammation, oxidative effects, cytokine activity, and endothelial damage, and lead to an accelerated atherosclerotic process [17]. The pathophysiological scenario of radiation-induced cardiovascular disease encompasses direct damage to the coronary arteries, fibrosis of the pericardium and myocardium, microvascular damage, and valve stenosis [18-20]. In this context, atherosclerotic changes play a major role. Endothelial cells are sensitive to radiation and radiation doses $\geq 2$ Gy can induce inflammatory effects which result in arteriosclerosis [20, 21]. This coronary damage can lead to perfusion deficiencies, ischemia, and myocardial fibrosis [20]. Beyond this, no valid evidence exists for radiation-induced atherosclerotic effects [20].

\section{Angiographic findings}

To assess a possible correlation between breast RT and the subsequent locations of coronary stenoses, Nilsson et al. [22] investigated 199 women with invasive breast cancer or ductal carcinoma in situ within a cohort irradiated between 


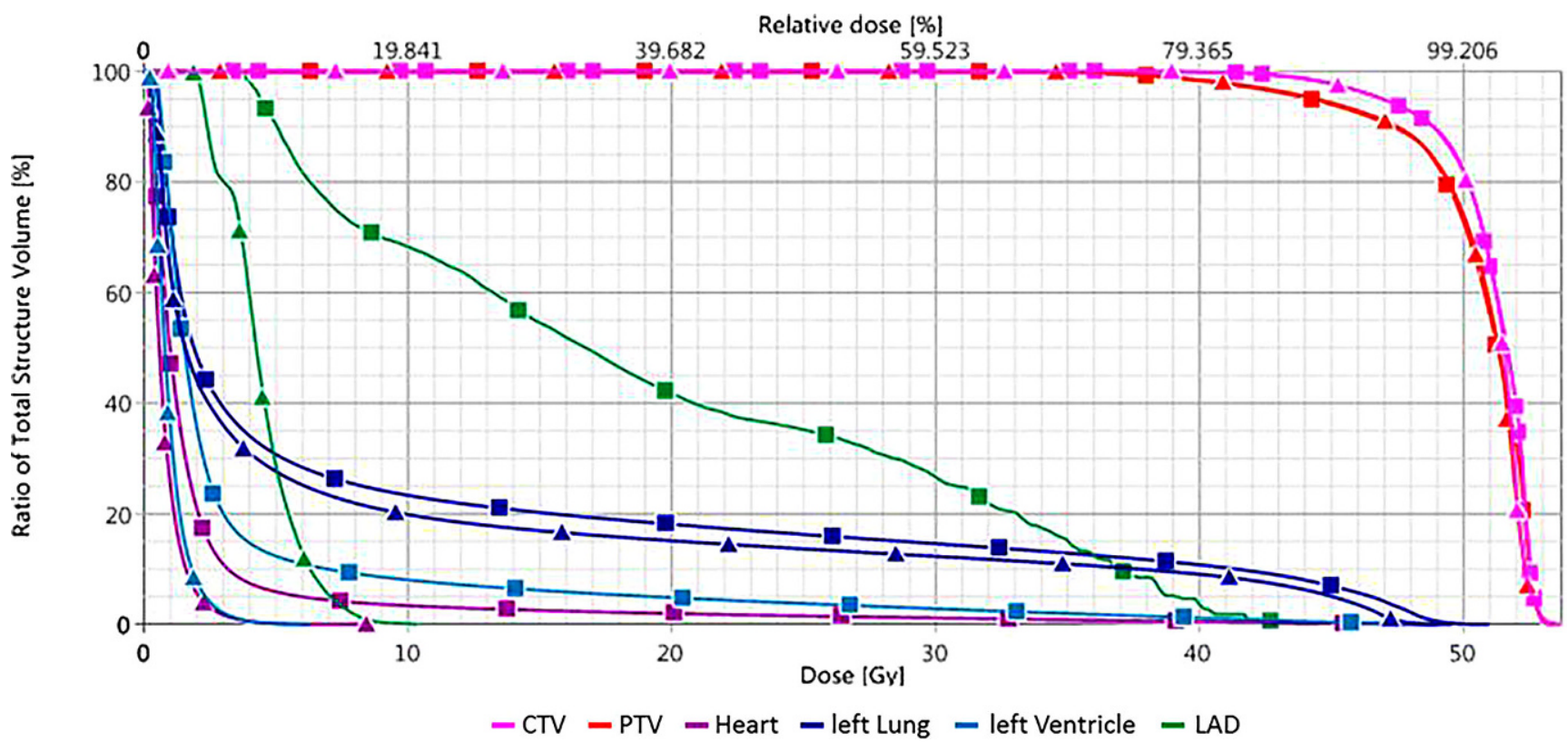

Fig. 2 Dose-volume histogram from the two treatment plans shown in Fig. 1. Graphs with triangles: with deep inspiration breathold (DIBH); graphs with squares: without DIBH. Planning target volume (PTV) in red, clinical target volume (CTV) in pink, whole heart in purple, left ventricle in light blue, left anterior descending artery $(L A D)$ in green, left lung in dark blue
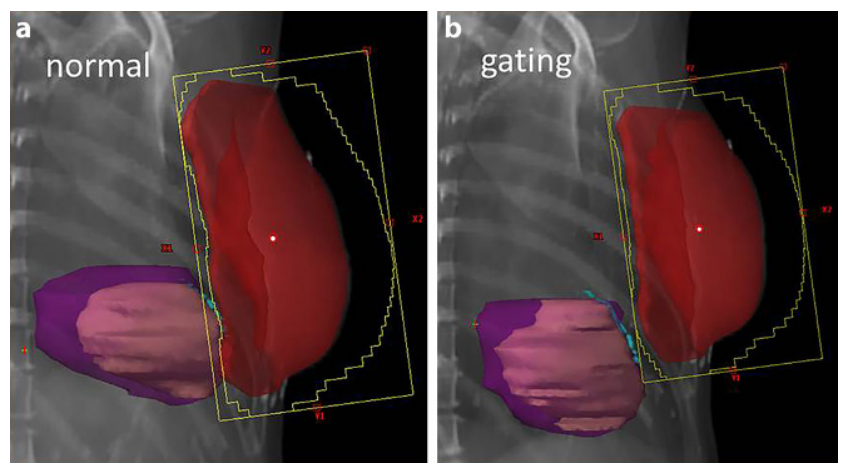

Fig. 3 Digital reconstructions from the two treatment plans. a Planning with normal breathing without deep-inspiration breathold (DIBH); b the same patient planned using gating with DIBH. Planning target volume in red, heart in purple, left ventricle in bright purple, left anterior descending artery contoured in light blue

1970 and 2003, who then received coronary angiography during the period from 1990 to 2004. The median interval from breast cancer to coronary angiography was 10.3 years ( $25^{\text {th }}$ percentile 5.4 years; $75 \%$ percentile 15.8 years). During the study period (1970 to 2003), several different RT regimens were used. Therefore, Nilsson et al. divided the respective RT concepts into high or low risk, depending on the estimated doses to so called hotspot areas, which were defined as follows: the proximal right coronary artery (prox. RCA) and the "mid and distal left anterior descending artery and distal diagonal" (mdLAD $+\mathrm{dD})$. The authors found an increase in clinically significant coronary artery stenoses in the predefined hotspot areas in patients who un- derwent left-sided WBI/chest wall RT compared to patients who did not receive RT to these areas. Radiation to the left breast/chest wall was considered as high-risk RT and was associated with an increased risk of coronary artery stenoses in mdLAD $+\mathrm{dD}$, with a 4- to 7-fold risk increase in significant stenoses for the mid and distal LAD in radiation hotspot areas. The authors concluded that the findings indicate a direct link between radiation and the location of coronary stenosis.

Moignier et al. analyzed the risk of coronary stenosis following Hodgkin lymphoma RT of the mediastinum [23]. The authors performed a 3D coronary artery dose calculation after mediastinal RT using coronary $\mathrm{CT}$ angiographies. Twelve patients developing coronary stenosis after mediastinal RT were matched to 21 irradiated patients without stenosis. Radiation doses to stenotic segments were compared with doses to normal segments. Based on these findings, the authors estimated the risk of coronary stenosis depending on the radiation dose to the coronary arteries. It could be shown that the coronary artery segment dose significantly increased the risk of stenosis in the segment. The median dose to the damaged vs. undamaged coronary segments was 30.3 vs. $26.3 \mathrm{~Gy}$ ( $25^{\text {th }}$ to $75^{\text {th }}$ percentile: around 26 to $40 \mathrm{~Gy}$ vs. 3.3 to $35 \mathrm{~Gy} ; p<0.001)$.

\section{Functional imaging}

Marks et al. analyzed myocardial perfusion in the cardiac apex 6, 12, 18, and 24 months after RT to the left breast [24]. In this prospective trial, 114 patients with left-sided breast 
Table 1 Comparison of mean and maximum doses to target volumes, heart and heart substructures, and left lung achieved performing treatment planning without and with DIBH (Fig. 1)

\begin{tabular}{lllll}
\hline & \multicolumn{2}{l}{ Mean dose $(\mathrm{Gy})$} & \multicolumn{2}{l}{ Maximum dose $(\mathrm{Gy})$} \\
\hline Structure & no DIBH & DIBH & no DIBH & DIBH \\
PTV & 50.4 & 50.4 & $52.8\left(\mathrm{D}_{2 \%}\right)$ & $52.9\left(\mathrm{D}_{2} \%\right)$ \\
CTV & 51.0 & 50.9 & $52.9\left(\mathrm{D}_{2 \%}\right)$ & $52.9\left(\mathrm{D}_{2 \%}\right)$ \\
$\begin{array}{l}\text { Whole } \\
\text { heart }\end{array}$ & 2.1 & 0.8 & 49.1 & 8.6 \\
$\begin{array}{l}\text { Left ven- } \\
\text { tricle }\end{array}$ & 3.8 & 1.0 & 49.1 & 6.2 \\
LAD & 19.3 & 4.4 & 44.6 & 10.4 \\
Left lung & 9.5 & 8.2 & 51.0 & 49.6 \\
\hline
\end{tabular}

$D I B H$ deep inspiration breathold; $L A D$ left anterior descending artery; $D_{2} \%$ dose exceeding $\leq 2 \%$ of the volume; $P T V$ planning target volume; $C T V$ clinical target volume

cancer were treated with 46-50 Gy using tangential photon beams. By inclusion of the cardiac apex into the radiation fields (by the authors' definition, equivalent to $>50 \%$ of the prescribed dose), new perfusion defects were detected in 27 , 29,38 , and $42 \%$ of patients after $6,12,18$, and 24 months, respectively. If $<5 \%$ versus $\geq 5 \%$ of the left ventricle was included into the radiation portals, perfusion defects were seen in $10-20 \%$ vs. $50-60 \%$ of patients, respectively.

\section{Strain rate imaging (Doppler echocardiography)}

Erven et al. analyzed early radiation-induced changes in regional cardiac function using the strain-rate imaging (SRI) method by Doppler echocardiography [25]. The authors included 20 left-sided and 10 right-sided breast cancer patients irradiated to the breast or chest wall. Echocardiography and SRI were performed before and immediately after the RT course and repeated 2 months thereafter. The LV was divided into 18 segments. Regional strain and strainrate values were analyzed from all segments and related to the radiation dose applied to the corresponding region. For the left-sided patients, a strain and strain-rate reduction could be seen post RT. In the apical segments receiving $>3$ Gy vs. <3 Gy, a significant decrease in strain expressed as a decrease in systolic myocardial deformation could be observed.

In line with this data, Heggemann et al. saw a decrease in longitudinal strain in apical segments after 24 months [26]. In this study, recorded doses to the apex were $34.4 \pm 10 \mathrm{~Gy}$.

\section{Serum biomarkers}

Focusing on cardiac biomarkers, D'Errico et al. found indications that not the mean dose but the percentage of organ volumes receiving doses much higher than the mean heart dose are relevant [27]. The authors demonstrated that car- diac biomarkers such as N-terminal pro-B-type natriuretic peptide (NT-proBNP) or troponin (TnI) increase after leftsided breast RT and evaluated the correlation between the respective plasma levels and the radiation dose to the heart. At mean 9 months after left-sided RT of the breast, NTproBNP levels were significantly higher compared to those of non-irradiated patients. No significant correlation was noted for mean heart dose and the biomarker levels. In contrast, the dosimetric parameters $\mathrm{V} 3_{\text {heart }}$ (percentage volume of the whole heart receiving $\geq 3 \mathrm{~Gy}$ ) and $\mathrm{V} 2_{\mathrm{LV}}$ (percentage volume of the $\mathrm{LV}$ receiving $\geq 2 \mathrm{~Gy}$ ) correlated significantly with NT-proBNP. Furthermore, several other dosimetric parameters were analyzed, focusing on small heart volumes receiving higher doses. For example, the increase of the ratio $\mathrm{D}_{15 \mathrm{~cm}^{3}}(\mathrm{~Gy}) / \mathrm{D}_{\text {mean }}(\mathrm{Gy})$ correlated significantly with the level of NT-proBNP. The authors stated that the most important parameter is not the mean dose, but rather the percentage of organ volumes receiving doses much higher than the mean heart dose.

Skyttä et al. found a positive correlation between cardiac doses and the serum biomarker troponin $\mathrm{T}$ (high-sensitivity cardiac troponin $\mathrm{T}$, hscTnT) [28]. In a prospective study, hscTnT was analyzed before, during, and immediately after finishing the course of RT. An increase in hscTnT of $>30 \%$ was interpreted as significant. In patients with such an hscTnT increase, the mean heart dose and mean LV dose were significantly higher (4 vs. 2.8Gy, $p=0.02$ and 6.7 vs. $4.5 \mathrm{~Gy} ; p=0.02)$. Furthermore, the mean LAD dose (17.5 vs. $23.8 \mathrm{~Gy})$ and V15 (58.6 vs. 40\%), V20 (55.4 vs. $36.2 \%$ ), and V30 (45 vs. $29.3 \mathrm{~Gy}$ ) for the LAD volume were significantly higher. The maximum LAD dose was also higher (43.4 vs. $37.8 \mathrm{~Gy}$ ), but not significantly.

A summary of several findings focusing on radiationinduced heart toxicity (see above) and deduced dose constraints for heart and subvolumes is given in Table 2.

\section{Discussion}

Even small heart doses are suspected to increase the risk of cardiac disease. Darby et al. estimated the proportional increase in the rate of major coronary events per Gray. This assumption was based on a retrospective evaluation using a population-based case-control study. Darby et al. found that the risk of major coronary events (i.e., myocardial infarction, coronary revascularization, deaths from ischemic heart disease) increased linearly with the increase in mean heart dose with no clear threshold [29]. They showed a dose-effect relationship with an increase in the relative risk of acute major coronary events of $7.4 \%$ per Gy $(95 \%$ confidence interval, CI: $2.9-14.5 ; p<0.001)$ mean heart dose within 20 years [29]. The increase started within the first 5 years after RT and continued into the third decade 
after RT. Although women with preexisting cardiac risk factors had greater absolute increases in the risk from RT, the proportional increase in the rate of major coronary events per Gy was similar in women with and without cardiac risk factors at the time of RT. Of note, for mean heart doses below $2 \mathrm{~Gy}$, no significantly increased event rates were seen.

Recently, the findings of Darby et al. were validated by van den Bogaard et al. [30]. The authors analyzed 3D dose distributions to the heart and cardiac substructures derived from CT planning scans of an independent cohort of patients with breast cancer treated by RT. Validating the model of Darby et al., the authors created a multivariable Cox re- gression model using the same prognostic and pretreatment risk factors (i. e., age, mean heart dose, history of ischemic heart disease, diabetes, chronic obstructive pulmonary disease, smoking, body mass index $\geq 30 \mathrm{~kg} / \mathrm{m}^{2}$ ).

Van den Bogaard et al. found a relative increase in the cumulative incidence of acute coronary events (ACE) of $16.5 \%$ per Gy (hazard ratio, HR: 1.165 ; $95 \%$ CI for HR: 1.006 to $1.350 ; p=0.042$ ) of mean heart dose within 9 years of RT.

Also for other tumor entities including lung cancer, Hodgkin lymphomas, or after mediastinal irradiation, the

Table 2 Summary of publications focusing radiation-induced heart toxicity based on several findings, and deduced doses for heart and subvolumes

\begin{tabular}{|c|c|c|c|c|c|}
\hline & $\begin{array}{l}\text { Year of } \\
\text { treatment }\end{array}$ & Method of detection & Time to effects & Heart or subvolume dose & Effect \\
\hline $\begin{array}{l}\text { Darby et al. } 2013 \\
\text { [29] }\end{array}$ & $1958-2001$ & $\begin{array}{l}\text { Retrospective } \\
\text { population-based } \\
\text { case-control study }\end{array}$ & $\begin{array}{l}\text { Within } 20 \text { years/ } \\
\text { within first } 4 \text { years } \\
\text { post RT }\end{array}$ & $\begin{array}{l}\text { Per } 1 \text { Gy mean heart dose } \\
\text { Note: no significances for } \\
\text { mean heart dose }<2 \mathrm{~Gy}\end{array}$ & $\begin{array}{l}\text { Increase of relative risk } \\
\text { for mayor coronary } \\
\text { events: } 7.4 \% / 16.3 \%\end{array}$ \\
\hline $\begin{array}{l}\text { van den Bogaard } \\
\text { et al. } 2017 \text { [30] }\end{array}$ & 2005-2008 & - & $\begin{array}{l}\text { Within } 9 \text { years } \\
\text { post RT }\end{array}$ & Per 1 Gy mean heart dose & $\begin{array}{l}16.5 \% \text { increase in cu- } \\
\text { mulative incidence (HR } \\
1.165) \text { for acute coro- } \\
\text { nary events }\end{array}$ \\
\hline $\begin{array}{l}\text { van den Bogaard } \\
\text { et al. } 2017 \text { [30] }\end{array}$ & 2005-2008 & - & $\begin{array}{l}\text { Within } 9 \text { years } \\
\text { post RT }\end{array}$ & V5LV: $29.3 \%$ vs. $16.9 \%$ & $\begin{array}{l}\text { Acute coronary event vs } \\
\text { no }\end{array}$ \\
\hline $\begin{array}{l}\text { Carr et al. } 2005 \\
{[32]}\end{array}$ & $1937-1965$ & $\begin{array}{l}\text { Retrospective anal- } \\
\text { ysis, estimating car- } \\
\text { diac data }\end{array}$ & 22.5 years & $\begin{array}{l}\text { Whole heart dose } \geq 2.8 \\
(2.6-3) \text { Gy and } 5 \% \text { volume } \\
\text { of the heart (apex) } \geq 12.9 \\
(12-13.9) \text { Gy }\end{array}$ & $\begin{array}{l}\text { Significant increase in } \\
\text { coronary heart disease: } \\
\text { relative risk } 1.54 ; 95 \% \\
\text { CI: } 1.15-2.06\end{array}$ \\
\hline \multirow[t]{2}{*}{$\begin{array}{l}\text { Marks et al. } 2005 \\
\text { [24] }\end{array}$} & \multirow[t]{2}{*}{ 1998-2001 } & \multirow[t]{2}{*}{$\begin{array}{l}\text { Cardiac SPECT } \\
\text { imaging }\end{array}$} & \multirow[t]{2}{*}{ 6-24 months } & $\begin{array}{l}\text { Cardiac apex included into } \\
\text { the radiation fields (i.e., } \\
>23-25 \mathrm{~Gy} ; 1.8-2 \mathrm{~Gy} \text { per } \\
\text { day) }\end{array}$ & $\begin{array}{l}27-42 \% \text { new perfusion } \\
\text { defects in cardiac apex }\end{array}$ \\
\hline & & & & $\begin{array}{l}<5 \% \text { vs. } \geq 5 \% \text { of the left } \mathrm{LV} \\
\text { into the radiation fields }\end{array}$ & $\begin{array}{l}\text { Perfusion defects in } \\
10-20 \% \text { vs. } 50-60 \% \text { of } \\
\text { patients }\end{array}$ \\
\hline $\begin{array}{l}\text { Nilsson et al. } \\
2012 \text { [22] }\end{array}$ & 1970-2003 & Angiography & 10.3 years & $\begin{array}{l}\text { Coronary arteries within } \\
\text { (or near) the tangential } \\
\text { radiation field, so called } \\
\text { hotspot areas: mid, distal, } \\
\text { and distal diagonal branch } \\
\text { of LAD }\end{array}$ & $\begin{array}{l}\text { Stenosis in LAD (mid, } \\
\text { distal and distal diagona } \\
\text { branch of LAD) }\end{array}$ \\
\hline $\begin{array}{l}\text { Moignier et al. } \\
2015 \text { [23] }\end{array}$ & 2000-2008 & $\begin{array}{l}\text { Coronary CT angiog- } \\
\text { raphy }\end{array}$ & Median 6 years & $\begin{array}{l}\text { Coronary artery segments: } \\
\text { median } 30.3 \text { Gy vs. } 26.3 \mathrm{~Gy}\end{array}$ & Coronary stenosis \\
\hline \multirow[t]{5}{*}{$\begin{array}{l}\text { Skyttä et al. } 2015 \\
{[28]}\end{array}$} & \multirow[t]{5}{*}{$2011-2013$} & \multirow[t]{5}{*}{ Serum troponin $\mathrm{T}$} & \multirow[t]{5}{*}{9 months (mean) } & $\begin{array}{l}\text { Mean heart dose: } 4 \text { Gy vs. } \\
2.8 \mathrm{~Gy}\end{array}$ & \multirow{5}{*}{$\begin{array}{l}\text { Increase of serum } \\
\text { troponin } \mathrm{T} \\
(\mathrm{hscTNT})>30 \%\end{array}$} \\
\hline & & & & $\begin{array}{l}\text { Mean LV dose: } 6.7 \text { vs. } \\
4.5 \mathrm{~Gy}\end{array}$ & \\
\hline & & & & $\begin{array}{l}\text { Mean LAD dose: } 23.8 \text { vs. } \\
17.5 \mathrm{~Gy}\end{array}$ & \\
\hline & & & & V20LAD: $55.4 \%$ vs. $36.2 \%$ & \\
\hline & & & & V30LAD: $45 \%$ vs. $29.3 \%$ & \\
\hline $\begin{array}{l}\text { Erven et al. } 2011 \\
{[25]}\end{array}$ & - & $\begin{array}{l}\text { Regional strain value, } \\
\text { detected by Doppler } \\
\text { echocardiography }\end{array}$ & $\begin{array}{l}\text { Immediately after } \\
\text { RT and } 2 \text { months } \\
\text { after RT }\end{array}$ & $\begin{array}{l}\text { Left apical ventricular } \\
\text { segments }>3 \text { Gy vs. }<3 \text { Gy }\end{array}$ & $\begin{array}{l}\text { Significant decrease } \\
\text { in strain respectively } \\
\text { systolic myocardial } \\
\text { function }\end{array}$ \\
\hline
\end{tabular}

$L V$ left ventricle; $L A D$ left anterior descending artery; $V x_{L V}$ percent of left ventricle volume receiving $\geq \mathrm{x}$ Gy, $H R$ hazard ratio, $S P E C T$ single-photon emission computed tomography, hscTNT high-sensitivity cardiac troponin T, $R T$ radiotherapy 
Table 3 Dose constraints for heart and substructures in breast radiotherapy

\begin{tabular}{lll}
\hline Volume & Constraint & Value \\
\hline Whole heart & Mean heart dose & $<2.5 \mathrm{~Gy}$ \\
Left ventricle & $\mathrm{D}_{\text {mean }} \mathrm{LV}$ & $<3 \mathrm{~Gy}$ \\
& V5 $5_{\mathrm{LV}}$ & $<17 \%$ \\
& V23LV & $<5 \%$ \\
LAD & D $_{\text {mean LAD }}$ & $<10 \mathrm{~Gy}$ \\
& V30 & $<2 \%$ \\
& V40 & $<1 \%$ \\
\hline
\end{tabular}

$L V$ left ventricle; $L A D$ left anterior descending artery; $D_{\text {mean }}$ mean dose of the volume; $V x_{L V}$ percent of left ventricle volume receiving $\geq \mathrm{x}$ Gy

mean heart dose is known to be a relevant parameter for prediction of all-cause cardiac toxicities [31].

Examining the context of coronary heart disease and RT, interesting data were yielded by Carr et al. based on a patient cohort treated with RT for peptic ulcer disease [32]. Although this treatment indication is historical, the data provide indications to further understand the relationship between total heart dose and the dose to the apex. The authors analyzed data of 3719 patients irradiated for peptic ulcer disease between 1937 and 1965 using orthovoltage $\mathrm{X}$-rays encompassing the stomach by anterior and posterior opposing fields. The daily and total doses were 1.5 and $16-17 \mathrm{~Gy}$, respectively. The authors estimated that $5 \%$ of the cardiac volume, generally apex volume, was included into the radiation field and received 7.6-18.4 Gy. The estimated dose to the cardiac volume outside of the radiation field was $1.6-3.9 \mathrm{~Gy}$.

The authors found a statistically significant increase in coronary heart disease in patients with an estimated whole heart dose of $2.8 \mathrm{~Gy}$ and $12.9 \mathrm{~Gy}$ to $5 \%$ of the cardiac volume (relative risk 1.54; 95\% CI: 1.15-2.06). A mean whole heart dose of $1.6 \mathrm{~Gy}$ accompanied with an in-field dose (to the apex) of $7.6 \mathrm{~Gy}$ led to no increase in the relative risk for coronary heart disease.

\section{Time-factor}

For a comprehensive assessment of coronary artery disease (CAD) risk in the context of breast irradiation, the time factor seems to be highly important, but data related to this are not entirely consistent.

Darby et al. impressively demonstrated that the risk of CAD continuously increased with time after finishing breast irradiation. The increase in risk began within the first 5 years after radiation and continued for at least 20 years [7]. Considering all major coronary events detected within the time span of 0 to 20 years after RT, the relative risk increased by $7.4 \%$ per Gy. Interestingly, in the study by Darby et al., the strongest increase in relative risk of major coronary events was seen within the first 4 years, with a rate of $16.3 \%$ per Gy.

To examine whether the risk of cardiac death was higher in the second than in the first follow-up decade after RT, Harris et al. performed a cumulative hazard risk estimation based on data of patients irradiated between 1977 and 1994 [9]. For left-sided patients, the cumulative risk of cardiac deaths was $1.9 \%$ (95\% CI, 0.09 to 3.9\%) after 10 years and $6.4 \%$ (95\% CI, 3.5 to $11.5 \%$ ) after 20 years. In comparison, for right-sided radiation, the cumulative risk increased from $1.5 \%$ to $3.6 \%$ in the same time span.

\section{Further factors affecting cardiac risk}

It should be acknowledged that several other factors affect the cardiac risk. The risk for cardiotoxicity as well as its severity depends on many factors and is further determined by the presence of traditional cardiovascular risk factors, particularly cardiometabolic risk factors such as diabetes mellitus, arterial hypertension, dyslipidemia, and obesity. Preexisting cardiovascular diseases such as arrhythmia, myopathy, or chronic ischemic heart disease represent further risk factors.

\section{Smoking}

Smoking is a highly relevant risk factor potentiating the risk of radiogenic heart damage after left-sided breast RT. The increase in absolute risk in radiation-related cardiac mortality is more pronounced in smokers than in nonsmokers. In general, the mortality from heart disease is much higher for smokers than nonsmokers. Based on European female death rate data, the estimated risk of death before reaching an age of 80 years was $1.8 \%$ for a nonsmoker and $8.0 \%$ for a smoker [33]. Based on these data and supposing a mean heart dose of $4.4 \mathrm{~Gy}$, Taylor et al. calculated an absolute increase in cardiac mortality related to RT of $0.3 \%$ for nonsmokers (1.8 to $2.1 \%$ ) and $1.2 \%$ for smokers $(8.0$ to $9.2 \%)$ [34].

\section{Systemic treatments}

The contribution of chemotherapy in addition to RT remains an important aspect in the development of cardiac disease in cancer patients and plays an important role as a further risk factor. Anthracyclines and trastuzumab are notorious anticancer drugs and responsible for the development of cardiac disease.

Chemotherapy-induced cardiotoxicity is distinguished into type 1 (anthracycline) and type 2 (trastuzumab). In type 1 , structural damage to the cardiomyocytes is induced and must be considered irreversible. Type 2 is character- 
ized by the lack of structural changes, so that the end of therapy usually brings complete recovery; thus, the damage is reversible. Other substances with cardiotoxic effects are, for example, cyclophosphamide, clofarabine, fluorouracil, vincristine, interferon-alpha-2b, sunitinib, and sorafenib $[35,36]$.

\section{Risk-factor assessment}

To improve the safety of patients with breast cancer before starting chest RT, patients should undergo a baseline assessment for RIHD risk factors and, in case of preexistent risk factors, a thorough clinical examination, a baseline echocardiography evaluation, and possibly further diagnostics as recommended by the European Association of Cardiovascular Imaging of the European Society of Cardiology and the American Society of Echocardiography expert group [37-39].

\section{Value of mean heart dose}

The key question is: Is the mean heart dose able to predict the risk of acute cardiac events?

In principle, mean heart dose seems to be a valid parameter for predicting cardiac toxicity. It is well-documented that reducing the mean heart dose is associated with lower risks of cardiac late effects [10, 12, 22, 29, 40]. Using modern techniques for breast irradiation, low mean heart does in a range below 2-3Gy are achievable. Despite such low mean heart doses, subvolumes such as the heart apex or parts of the LAD can be exposed to much higher doses (Figs. 1 and 2; [41]). In a study conducted by the authors using a modern $3 \mathrm{D}$ technique with tangential beams to treat left-sided breast cancer, the mean heart dose amounted 2.1 (0.98-8.3) Gy [42]. Nonetheless, maximum doses to small but presumably relevant parts of the anterior part of the LV ("anterior myocardial territory," AMT; based on Tan et al. [43]) were up to $47.2 \mathrm{~Gy}$. The mean and maximum doses to the LAD were $9.2(2.1-46.2) \mathrm{Gy}$ and 24.6 (2.8-49.6) Gy, respectively.

The problem is illustrated in Figs. 1 and 2. In Fig. 1, radiation treatment planning scans (transversal planes) of the left breast are shown. In both cases, modern 3D planning was performed. Even without any specific heart-protecting technique, the mean heart dose is below 2.5 Gy. Nevertheless, apical areas like the LAD and LV receive much higher doses.

The question of which parts of the heart are of highest relevance for late effects-thus implying the necessity of their optimal protection-is not definitively answered. Without prejudice to the fact that there is an increased radiogenic risk for cardiac damage after left-sided breast can- cer RT, there are no clear constraints and thresholds with respect to absolute doses and (sub)volumes.

Considering the available data, it seems to be reasonable to define several parts of the heart, especially the anterior part, as organs at risk (OAR). For example, in a comparative dosimetric study, Tan et al. demonstrated that using the AMT as an OAR in left-sided breast intensity-modulated RT (IMRT), the radiation dose to the heart could be reduced [43, 44].

But what is the threshold dose for heart disease regarding the whole heart and its substructures? What is a potentially safe dose cut-off?

To date, based on the available literature and considering the lack of more detailed prospective data, the dose constraints to heart and subvolumes shown in Table 3 seem to be reasonable.

More restrictively, considering the data from Carr et al. [32] for the whole heart, a mean heart dose $<1.6 \mathrm{~Gy}$ and a V13<5\% could also be justifiable. As a matter of course, doses to the heart and subvolumes should be kept as low as possible.

\section{Radiation to the breast and regional lymph nodes}

The suggested constraints have largely been developed for adjuvant whole-breast RT. In cases of comprehensive regional irradiation including the internal mammary lymph nodes, exceeding these constraints may be unavoidable and justifiable.

\section{Hypofractionation}

Hypofractionation (40-42.5 Gy with daily doses of 2.5$2.67 \mathrm{~Gy}$ ) has recently become the standard for adjuvant RT to the breast [45]. The available data for estimation of radiation-induced cardiac risks mostly refer to normal fractionation regimes, but are these experiences applicable to hypofractionation regimes?

From a radiobiological perspective, heart and coronary vessels are late-responding tissues. Generally, an $\alpha / \beta$ value $=3 \mathrm{~Gy}$ has been assumed for late-responding tissues and based on rat heart studies, even lower values may be suggested, possibly as low as $1 \mathrm{~Gy}$ [46, 47]. Such tissues are particularly sensitive to increasing fraction doses. Appelt et al. estimated the fraction size-corrected dose to the heart for hypofractionation regimens based on the linear quadratic model [47]. Dose distributions of hypofractionated treatment plans were corrected to the equivalent dose in 2 Gy fractions (EQD2) using the linear quadratic model for normal fractionation and four hypofractionation 
regimens. The tested range of $\alpha / \beta$ values was from 0 to $5 \mathrm{~Gy}$. The authors stated that for $\alpha / \beta \geq 1.5 \mathrm{~Gy}$, the hypofractionation regimens using $40 \mathrm{~Gy}$ ( $2.67 \mathrm{~Gy}$ daily), $42.5 \mathrm{~Gy}$ (2.65 Gy daily), and $39 \mathrm{~Gy}$ ( $3 \mathrm{~Gy}$ daily) result in lower equivalent doses to the heart than the normal fractionation regime (50 Gy/2 Gy).

These findings are in line with the clinical results of the randomized Canadian and Start B trials, where no increased cardiac toxicity was seen in the hypofractionation treatment arms [48, 49]. Recently, James et al. also observed no differences in ischemic heart toxicities when comparing normal and hypofractionated breast treatment [50].

\section{Technical options reducing heart dose}

Several technical options are available to limit the mean heart dose or to specifically spare selected subvolumes of the heart such as the coronary arteries. Whereas tangential IMRT or field-in-field approaches are useful to avoid hotspots at the skin or within the breast in order to improve cosmetic outcome and reduce the risk of fibrosis, no relevant sparing of the heart and lungs can be achieved [51]. Multiangle or rotational IMRT delivery can be used to create concave dose distributions and to reduce the high dose volume of the lung and heart abutting the chest wall at the cost of a low-dose bath to the ipsi- and contralateral lung and the whole heart [52]. DIBH-based radiation therapy can help to distance the heart from the chest wall and reduce the dose to the heart and substructures such as the LAD [53-56]; Figs. 1, 2 and 3. In selected cases, especially with pendulous breasts, prone positioning can result in favorable geometry with distancing of the target volume away from the chest wall, whilst at the same time moving the heart closer to the chest wall. Alternatively, the usefulness of a thermoplastic bra in terms of dose reduction to heart and lung substructures has been demonstrated [42]. Finally, partial-breast RT is an option in elderly patients with lowrisk cancer, especially when no adequate sparing of heart and lung can be achieved during WBI [57-59].

\section{Conclusion}

Heart toxicities due to RT of the breast-particularly leftsided breast RT - are rare but clearly recognizable. Modern techniques permit sufficient protection of the heart and lungs in most cases. However, in some instances, i.e. in patients with unfavorable anatomy, subvolumes of the heart-particularly apical regions such as the LV or the LAD_receive high doses despite low mean heart doses.

Valid data defining dose constraints to subvolumes of the heart are sparse. In the current report, the authors propose dose constraints to the heart and its subvolumes to achieve an adequate heart protection and which may be achievable in conventional and hypofractionated regimens. The suggested constraints apply to left-sided breast RT only. For several kinds of breast irradiation, particularly if lymph nodes must be included, these constraints are not achievable.

Furthermore, patient-specific cardiac risk factors and the individual breast cancer-related risk constellation must be considered. The patient's breast cancer mortality risk and cardiac risk factors must be individually interrelated to possible radiation-induced heart toxicities. The final and individual decision between protection of heart volumes and target volume coverage remains in the physician's hand.

Conflict of interest M.D. Piroth, R. Baumann, W. Budach, J. Dunst, P. Feyer, R. Fietkau, W. Haase, W. Harms, T. Hehr, D. Krug, A. Röser, F. Sedlmayer, R. Souchon, F. Wenz, and R. Sauer declare that they have no competing interests.

Open Access This article is distributed under the terms of the Creative Commons Attribution 4.0 International License (http:// creativecommons.org/licenses/by/4.0/), which permits unrestricted use, distribution, and reproduction in any medium, provided you give appropriate credit to the original author(s) and the source, provide a link to the Creative Commons license, and indicate if changes were made.

\section{References}

1. Clark RM, Whelan T, Levine M et al (1996) Randomized clinical trial of breast irradiation following lumpectomy and axillary dissection for node-negative breast cancer: an update. Ontario Clinical Oncology Group. J Natl Cancer Inst 88(22):1659-1664

2. Fisher B, Anderson S, Redmond CK et al (1995) Reanalysis and results after 12 years of follow-up in a randomized clinical trial comparing total mastectomy with lumpectomy with or without irradiation in the treatment of breast cancer. N Engl J Med 333(22):1456-1461. https://doi.org/10.1056/NEJM199511303332 203

3. Clarke M, Collins R, Darby S et al (2005) Effects of radiotherapy and of differences in the extent of surgery for early breast cancer on local recurrence and 15-year survival: an overview of the randomised trials. Lancet 366(9503):2087-2106. https://doi.org/10. 1016/S0140-6736(05)67887-7

4. Cuzick J, Stewart H, Rutqvist L et al (1994) Cause-specific mortality in long-term survivors of breast cancer who participated in trials of radiotherapy. J Clin Oncol 12(3):447-453

5. Darby S, McGale P, Peto R et al (2003) Mortality from cardiovascular disease more than 10 years after radiotherapy for breast cancer: nationwide cohort study of 90000 Swedish women. BMJ 326(7383):256-257

6. Roychoudhuri R, Robinson D, Putcha V et al (2007) Increased cardiovascular mortality more than fifteen years after radiotherapy for breast cancer: a population-based study. BMC Cancer 7:9. https:// doi.org/10.1186/1471-2407-7-9

7. Darby SC, McGale P, Taylor CW et al (2005) Long-term mortality from heart disease and lung cancer after radiotherapy for early breast cancer: prospective cohort study of about 300,000 women in US SEER cancer registries. Lancet Oncol 6(8):557-565. https:// doi.org/10.1016/S1470-2045(05)70251-5 
8. Bouillon K, Haddy N, Delaloge S et al (2011) Long-term cardiovascular mortality after radiotherapy for breast cancer. J Am Coll Cardiol 57(4):445-452. https://doi.org/10.1016/j.jacc.2010.08.638

9. Harris EE, Correa C, Hwang WT et al (2006) Late cardiac mortality and morbidity in early-stage breast cancer patients after breast-conservation treatment. J Clin Oncol 24(25):4100-4106. https://doi. org/10.1200/JCO.2005.05.1037

10. Taylor CW, Nisbet A, McGale P et al (2007) Cardiac exposures in breast cancer radiotherapy: 1950s-1990s. Int J Radiat Oncol Biol Phys 69(5):1484-1495. https://doi.org/10.1016/j.ijrobp.2007.05. 034

11. Taylor CW, Nisbet A, McGale P et al (2009) Cardiac doses from Swedish breast cancer radiotherapy since the 1950s. Radiother Oncol 90(1):127-135. https://doi.org/10.1016/j.radonc.2008.09.029

12. Taylor CW, Povall JM, McGale P et al (2008) Cardiac dose from tangential breast cancer radiotherapy in the year 2006. Int J Radiat Oncol Biol Phys 72(2):501-507. https://doi.org/10.1016/j.ijrobp. 2007.12.058

13. Weberpals J, Jansen L, Muller OJ et al (2018) Long-term heartspecific mortality among 347476 breast cancer patients treated with radiotherapy or chemotherapy: a registry-based cohort study. Eur Heart J. https://doi.org/10.1093/eurheartj/ehy167

14. Andratschke N, Maurer J, Molls M et al (2011) Late radiation-induced heart disease after radiotherapy. Clinical importance, radiobiological mechanisms and strategies of prevention. Radiother Oncol 100(2):160-166. https://doi.org/10.1016/j.radonc.2010.08.010

15. Becker-Schiebe M, Stockhammer M, Hoffmann W et al (2016) Does mean heart dose sufficiently reflect coronary artery exposure in left-sided breast cancer radiotherapy? : influence of respiratory gating. Strahlenther Onkol 192(9):624-631. https://doi.org/10. 1007/s00066-016-1011-y

16. Duma MN, Munch S, Oechsner M et al (2017) Are heart toxicities in breast cancer patients important for radiation oncologists? A practice pattern survey in German speaking countries. BMC Cancer 17(1):563. https://doi.org/10.1186/s12885-017-3548-2

17. Mehta LS, Watson KE, Barac A, Beckie TM (2018) Cadiovascular disease and breast cancer: where these entities intersect. Circulation 137(8):e30. https://doi.org/10.1161/CIR.0000000000000556

18. Tapio S (2016) Pathology and biology of radiation-induced cardiac disease. J Radiat Res 57(5):439-448. https://doi.org/10.1093/ jrr/rrw064

19. Adams MJ, Hardenbergh PH, Constine LS et al (2003) Radiation-associated cardiovascular disease. Crit Rev Oncol Hematol 45(1):55-75

20. Stewart FA, Seemann I, Hoving S et al (2013) Understanding radiation-induced cardiovascular damage and strategies for intervention. Clin Oncol (R Coll Radiol) 25(10):617-624. https://doi.org/ 10.1016/j.clon.2013.06.012

21. Lusis AJ (2000) Atherosclerosis. Nature 407(6801):233-241. https://doi.org/10.1038/35025203

22. Nilsson G, Holmberg L, Garmo H et al (2012) Distribution of coronary artery stenosis after radiation for breast cancer. J Clin Oncol 30(4):380-386. https://doi.org/10.1200/JCO.2011.34.5900

23. Moignier A, Broggio D, Derreumaux S et al (2015) Coronary stenosis risk analysis following Hodgkin lymphoma radiotherapy: A study based on patient specific artery segments dose calculation. Radiother Oncol 117(3):467-472. https://doi.org/10.1016/j.radonc. 2015.07.043

24. Marks LB, Yu X, Prosnitz RG et al (2005) The incidence and functional consequences of RT-associated cardiac perfusion defects. Int J Radiat Oncol Biol Phys 63(1):214-223. https://doi.org/10.1016/j. ijrobp.2005.01.029

25. Erven K, Jurcut R, Weltens C et al (2011) Acute radiation effects on cardiac function detected by strain rate imaging in breast cancer patients. Int J Radiat Oncol Biol Phys 79(5):1444-1451. https://doi. org/10.1016/j.ijrobp.2010.01.004
26. Heggemann F, Grotz H, Welzel G et al (2015) Cardiac function after multimodal breast cancer therapy assessed with functional magnetic resonance imaging and echocardiography imaging. Int $\mathrm{J}$ Radiat Oncol Biol Phys 93(4):836-844. https://doi.org/10.1016/j. ijrobp.2015.07.2287

27. D'Errico MP, Grimaldi L, Petruzzelli MF et al (2012) N-terminal pro-B-type natriuretic peptide plasma levels as a potential biomarker for cardiac damage after radiotherapy in patients with left-sided breast cancer. Int J Radiat Oncol Biol Phys 82(2): e239-e246. https://doi.org/10.1016/j.ijrobp.2011.03.058

28. Skytta T, Tuohinen S, Boman E et al (2015) Troponin T-release associates with cardiac radiation doses during adjuvant left-sided breast cancer radiotherapy. Radiat Oncol 10:141. https://doi.org/10. 1186/s13014-015-0436-2

29. Darby SC, Ewertz M, McGale P et al (2013) Risk of ischemic heart disease in women after radiotherapy for breast cancer. N Engl J Med 368(11):987-998. https://doi.org/10.1056/NEJMoa1209825

30. van den Bogaard VA, Ta BD, van der Schaaf A et al (2017) Validation and modification of a prediction model for acute cardiac events in patients with breast cancer treated with radiotherapy based on three-dimensional dose distributions to cardiac substructures. J Clin Oncol 35(11):1171-1178. https://doi.org/10.1200/JCO.2016. 69.8480

31. Hahn E, Jiang H, Ng A et al (2017) Late cardiac toxicity after mediastinal radiation therapy for Hodgkin Lymphoma: contributions of coronary artery and whole heart dose-volume variables to risk prediction. Int J Radiat Oncol Biol Phys 98(5):1116-1123. https:// doi.org/10.1016/j.ijrobp.2017.03.026

32. Carr ZA, Land CE, Kleinerman RA et al (2005) Coronary heart disease after radiotherapy for peptic ulcer disease. Int J Radiat Oncol Biol Phys 61(3):842-850. https://doi.org/10.1016/j.ijrobp.2004.07. 708

33. Pirie K, Peto R, Reeves GK et al (2013) The 21st century hazards of smoking and benefits of stopping: a prospective study of one million women in the UK. Lancet 381(9861):133-141. https://doi. org/10.1016/S0140-6736(12)61720-6

34. Taylor C, Correa C, Duane FK et al (2017) Estimating the risks of breast cancer radiotherapy: evidence from modern radiation doses to the lungs and heart and from previous randomized trials. J Clin Oncol 35(15):1641-1649. https://doi.org/10.1200/JCO.2016.72. 0722

35. Jain D, Russell RR, Schwartz RG et al (2017) Cardiac complications of cancer therapy: pathophysiology, identification, prevention, treatment, and future directions. Curr Cardiol Rep 19(5):36. https:// doi.org/10.1007/s11886-017-0846-x

36. Dong J, Chen H (2018) Cardiotoxicity of anticancer therapeutics. Front Cardiovasc Med 5:9. https://doi.org/10.3389/fcvm.2018. 00009

37. Rygiel K (2017) Cardiotoxic effects of radiotherapy and strategies to reduce them in patients with breast cancer: an overview. J Cancer Res Ther 13(2):186-192. https://doi.org/10.4103/0973-1482. 187303

38. Duma MN, Molls M, Trott KR (2014) From heart to heart for breast cancer patients-cardiovascular toxicities in breast cancer radiotherapy. Strahlenther Onkol 190(1):5-7. https://doi.org/10. 1007/s00066-013-0465-4

39. Zamorano JL, Lancellotti P, Rodriguez Munoz D et al (2016) 2016 ESC Position Paper on cancer treatments and cardiovascular toxicity developed under the auspices of the ESC Committee for Practice Guidelines: The Task Force for cancer treatments and cardiovascular toxicity of the European Society of Cardiology (ESC). Eur Heart J 37(36):2768-2801. https://doi.org/10.1093/eurheartj/ ehw211

40. Hooning MJ, Botma A, Aleman BM et al (2007) Long-term risk of cardiovascular disease in 10-year survivors of breast cancer. J Natl Cancer Inst 99(5):365-375. https://doi.org/10.1093/jnci/djk064 
41. Munshi A, Khataniar N, Sarkar B et al (2018) Spatial orientation of coronary arteries and its implication for breast and thoracic radiotherapy-proposing "coronary strip" as a new organ at risk. Strahlenther Onkol. https://doi.org/10.1007/s00066-018-1299-x

42. Piroth MD, Petz D, Pinkawa M et al (2016) Usefulness of a thermoplastic breast bra for breast cancer radiotherapy : a prospective analysis. Strahlenther Onkol 192(9):609-616. https://doi.org/10.1007/ s00066-016-0981-0

43. Tan W, Liu D, Xue C et al (2012) Anterior myocardial territory may replace the heart as organ at risk in intensity-modulated radiotherapy for left-sided breast cancer. Int J Radiat Oncol Biol Phys 82(5):1689-1697. https://doi.org/10.1016/j.ijrobp.2011.03.009

44. Tan W, Wang X, Qiu D et al (2011) Dosimetric comparison of intensity-modulated radiotherapy plans, with or without anterior myocardial territory and left ventricle as organs at risk, in earlystage left-sided breast cancer patients. Int J Radiat Oncol Biol Phys 81(5):1544-1551. https://doi.org/10.1016/j.ijrobp.2010.09.028

45. Wenz F, Budach W (2017) Personalized radiotherapy for invasive breast cancer in 2017 : National S3 guidelines and DEGRO and AGO recommendations. Strahlenther Onkol 193(8):601-603. https://doi.org/10.1007/s00066-017-1158-1

46. Lauk S, Ruth S, Trott KR (1987) The effects of dose-fractionation on radiation-induced heart disease in rats. Radiother Oncol 8(4):363-367

47. Appelt AL, Vogelius IR, Bentzen SM (2013) Modern hypofractionation schedules for tangential whole breast irradiation decrease the fraction size-corrected dose to the heart. Clin Oncol (r Coll Radiol) 25(3):147-152. https://doi.org/10.1016/j.clon.2012.07.012

48. Haviland JS, Owen JR, Dewar JA et al (2013) The UK Standardisation of Breast Radiotherapy (START) trials of radiotherapy hypofractionation for treatment of early breast cancer: 10-year follow-up results of two randomised controlled trials. Lancet Oncol 14(11):1086-1094. https://doi.org/10.1016/S14702045(13)70386-3

49. Whelan TJ, Pignol JP, Levine MN et al (2010) Long-term results of hypofractionated radiation therapy for breast cancer. N Engl J Med 362(6):513-520. https://doi.org/10.1056/NEJMoa0906260

50. James M, Swadi S, Yi M et al (2018) Ischaemic heart disease following conventional and hypofractionated radiation treatment in a contemporary breast cancer series. J Med Imaging Radiat Oncol 62(3):425-431. https://doi.org/10.1111/1754-9485.12712

51. Pignol JP, Olivotto I, Rakovitch E et al (2008) A multicenter randomized trial of breast intensity-modulated radiation therapy to re- duce acute radiation dermatitis. J Clin Oncol 26(13):2085-2092. https://doi.org/10.1200/JCO.2007.15.2488

52. Lohr F, El-Haddad M, Dobler B et al (2009) Potential effect of robust and simple IMRT approach for left-sided breast cancer on cardiac mortality. Int J Radiat Oncol Biol Phys 74(1):73-80. https:// doi.org/10.1016/j.ijrobp.2008.07.018

53. Boda-Heggemann J, Knopf AC, Simeonova-Chergou A et al (2016) Deep inspiration breath hold-based radiation therapy: a clinical review. Int J Radiat Oncol Biol Phys 94(3):478-492. https://doi.org/ 10.1016/j.ijrobp.2015.11.049

54. Schonecker S, Heinz C, Sohn M et al (2016) Reduction of cardiac and coronary artery doses in irradiation of left-sided breast cancer during inspiration breath hold : a planning study. Strahlenther Onkol 192(11):750-758. https://doi.org/10.1007/s00066-016$1039-\mathrm{z}$

55. Corradini S, Ballhausen H, Weingandt $\mathrm{H}$ et al (2018) Left-sided breast cancer and risks of secondary lung cancer and ischemic heart disease : effects of modern radiotherapy techniques. Strahlenther Onkol 194(3):196-205. https://doi.org/10.1007/s00066-017-1213y

56. Sakka M, Kunzelmann L, Metzger M et al (2017) Cardiac dosesparing effects of deep-inspiration breath-hold in left breast irradiation : Is IMRT more beneficial than VMAT? Strahlenther Onkol 193(10):800-811. https://doi.org/10.1007/s00066-017-1167-0

57. Coles CE, Griffin CL, Kirby AM et al (2017) Partial-breast radiotherapy after breast conservation surgery for patients with early breast cancer (UK IMPORT LOW trial): 5-year results from a multicentre, randomised, controlled, phase 3, non-inferiority trial. Lancet 390(10099):1048-1060. https://doi.org/10.1016/S01406736(17)31145-5

58. Vaidya JS, Wenz F, Bulsara M et al (2014) Risk-adapted targeted intraoperative radiotherapy versus whole-breast radiotherapy for breast cancer: 5-year results for local control and overall survival from the TARGIT-A randomised trial. Lancet 383(9917):603-613. https://doi.org/10.1016/S0140-6736(13)61950-9

59. Strnad V, Ott OJ, Hildebrandt G et al (2016) 5-year results of accelerated partial breast irradiation using sole interstitial multicatheter brachytherapy versus whole-breast irradiation with boost after breast-conserving surgery for low-risk invasive and in-situ carcinoma of the female breast: a randomised, phase 3, non-inferiority trial. Lancet 387 (10015):229-238. https://doi.org/10.1016/ S0140-6736(15)00471-7 


\title{
Affiliations
}

\section{Marc D. Piroth ${ }^{1} \cdot$ René Baumann²,4 Wilfried Budach ${ }^{3} \cdot$ Jürgen Dunst ${ }^{4} \cdot$ Petra Feyer $^{5} \cdot$ Rainer Fietkau $^{6}$. Wulf Haase ${ }^{7}$ Wolfgang Harms ${ }^{8}$. Thomas Hehr ${ }^{9}$. David Krug ${ }^{10,14}$ • Arnd Röser ${ }^{1}$. Felix Sedlmayer ${ }^{11}$. Rainer Souchon ${ }^{12} \cdot$ Frederik Wenz $^{13} \cdot$ Rolf Sauer $^{6}$}

\author{
René Baumann \\ R.Baumann@marienkrankenhaus.com \\ Wilfried Budach \\ wilfried.budach@med.uni-duesseldorf.de \\ Jürgen Dunst \\ juergen.dunst@uksh.de \\ Petra Feyer \\ petra.feyer@vivantes.de \\ Rainer Fietkau \\ rainer.fietkau@uk-erlangen.de \\ Wulf Haase \\ wulf.haase@t-online.de \\ Wolfgang Harms \\ wolfgang.harms@claraspital.ch \\ Thomas Hehr \\ thomas.hehr@vinzenz.de \\ David Krug \\ david.krug@med.uni-heidelberg.de \\ Arnd Röser \\ arnd.roeser@helios-gesundheit.de \\ Felix Sedlmayer \\ f.sedlmayer@salk.at \\ Rainer Souchon \\ r.souchon@t-online.de
}

\author{
Frederik Wenz \\ Frederik.wenz@umm.de \\ Rolf Sauer \\ rolf.sauer@uk-erlangen.de \\ 1 Helios University Hospital Wuppertal, Witten/Herdecke \\ University, Heusnerstraße 40, 42283 Wuppertal, Germany \\ 2 St. Marien-Krankenhaus Siegen, Siegen, Germany \\ 3 Heinrich-Heine-University Hospital Düsseldorf, Düsseldorf, \\ Germany \\ 4 University Hospital Schleswig-Holstein, Kiel, Germany \\ 5 Vivantes Hospital Neukoelln, Berlin, Germany \\ 6 University Hospital Erlangen, Erlangen, Germany \\ 7 formerly St.-Vincentius-Hospital Karlsruhe, Karlsruhe, Germany \\ 8 St. Claraspital Basel, Basel, Switzerland \\ 9 Marienhospital Stuttgart, Stuttgart, Germany \\ 10 University Hospital Heidelberg, Heidelberg, Germany \\ 11 Paracelsus Medical University Hospital Salzburg, Salzburg, \\ Austria \\ 12 formerly University Hospital, Tübingen, Germany \\ 13 University Hospital Mannheim, Medical Faculty, Heidelberg \\ University, Mannheim, Germany \\ 14 Heidelberg Institute for Radiation Oncology (HIRO), National \\ Center for Radiation Research in Oncology (NCRO), Heidelberg, \\ Germany
}

